\title{
Z

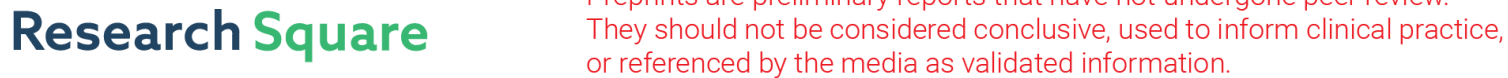 \\ Enhancing the radiological classification system from the distal femur to the proximal tibia
}

\section{Vincenzo de Matteo ( $\nabla$ dematteovincenzo@gmail.com )}

Federico II University Hospital: Azienda Ospedaliera Universitaria Federico II https://orcid.org/00000001-9638-8051

\section{Felipe Forero}

HELIOS Endo-Klinik Hamburg

\section{Sophia Marlene Busch}

HELIOS Endo-Klinik Hamburg

Philip Linke

HELIOS Endo-Klinik Hamburg

\section{Peter Wilhelm}

HELIOS Endo-Klinik Hamburg

Kristof Rademacher

HELIOS Endo-Klinik Hamburg

\section{Thorsten Gehrke}

HELIOS Endo-Klinik Hamburg

\section{Mustafa Citak}

HELIOS Endo-Klinik Hamburg https://orcid.org/0000-0003-3207-7101

\section{Research Article}

Keywords: Aseptic loosening, tibia, novel index, rotating hinge prosthesis, novel classification, revision arthroplasty

Posted Date: January 13th, 2022

DOI: https://doi.org/10.21203/rs.3.rs-1213550/v1

License: (c) (1) This work is licensed under a Creative Commons Attribution 4.0 International License. Read Full License

Version of Record: A version of this preprint was published at Joint Diseases and Related Surgery on March 28th, 2022. See the published version at https://doi.org/10.52312/jdrs.2022.602. 


\section{Abstract}

Introduction

The inner diaphyseal diameter of the distal femur, at $20 \mathrm{~cm}$ from the lateral joint line, is the strongest risk factor for predicting aseptic loosening in total knee arthroplasty using rotating hinge prosthesis. In this context, the Citak classification has been introduced presenting three different types of the distal femur anatomy. The aim of the study is to develop a novel classification system for the proximal tibia.

Materials and Methods

Two-hundred patients with standard knee antero-posterior radiographs were included in this study. We measured the inner diameter of the tibia $16 \mathrm{~cm}$ distally from the tibial plateau and $3 \mathrm{~cm}$ distally from the tibial spine. The ratio between these two measurements was applied as the novel index ratio.

Results

According to the 25th and 75th percentiles, three groups can be clustered for each gender. A higher distribution of the type B pattern was found in female and male patients. However, type A with a narrow inner diaphyseal diameter was less common in female patients The median intra-observer reliability for rater 1 was 0.997 . The inter-observer reliability was high (ICC 0.998).

There was a moderate correlation between the AP diameter and height $(r=0,568)$; a low correlation between the AP diameter and weight $(r=0.376)$. The novel index shows no significant correlation between the index ratio and height $(r=0.082)$, weight $(r=0.014)$ or BMI $(r=-0.038)$. The novel index shows no statistically significant correlation between the index ratio and height $(r=0.082)$ or weight $(r=$ $0.014)$ or BMI $(r=-0.038)$.

Conclusion

The novel classification presents three different types of tibia for each gender: type $C$ has a wider inner diaphyseal diameter compared to type A with a narrow inner diaphyseal diameter. Type B has the widest distribution among the subjects.

\section{Introduction}

Walldius developed in 1951 the first hinge system for primary knee arthroplasty (TKA) [1], a self-aligning stemmed device capable to achieve a great stability on the frontal plane (varus and valgus deviation), often substituting a deficient collateral ligament apparatus. The hinge system was very attractive due to his simplicity and efficacy, but this rigid system involved the transfer of torsional forces from the central hinge directly to the stems, generating high amount of stresses between the bone-cement interface and leading to complications such as fractures and mechanical failures. The introduction of rotating hinge implants in the 1970s[2] has improved the distribution of the rotational stresses providing better 
outcomes and reducing associated complications. These changes are represented in survivorship rates and functional knee scores as stated by Kouk et al [3].

In a recent meta-analysis, a rotating hinge knee design demonstrated an overall survival rate of $82 \%$ at 10 years with aseptic loosening $(A L)$ being the second cause of failure after infection (17.8\%), with an average joint age of 4.06 years [4]. Our institution's data shows a 14-fold higher incidence of AL at the femur compared to the tibial side; at the opposite, its most common localization (whether femur or tibia) is still debated in the literature [5-7]. Although the diagnosis can be straightforward and based on simple radiographs in the vast majority of the cases, this occurrence cannot always be predicted or avoided. Once detected, the loosening leads to a mandatory revision, considering that "conservative" approaches have not led to good results [8].

A recent article has demonstrated that the inner diaphyseal diameter of the distal femur $20 \mathrm{~cm}$ from the articular surface is one of the strongest independent risk factors related to aseptic loosening following primary TKA using cemented rotating hinge prosthesis [9]. Similar results have been presented for revision TKA procedures using cemented rotating hinge prosthesis by the same authors [10]. Subsequently, the novel radiological classification system, also known as Citak Classification, was introduced to the literature [5]. The Citak Classification divides the distal femur into three groups, where the population with a wider inner diaphyseal diameter is represented by type $\mathrm{C}$ with the highest risk for $\mathrm{AL}$ of the femoral component [9]. In this context, we aimed to identify anatomical variants of the proximal tibia shaft to develop a novel classification system for proximal tibia.

\section{Material And Methods}

\section{Study design}

Prior to the retrospective analysis, ethical approval was obtained from the institutional review board along with the local ethics committee (2021-300061-WF).

A total number of 554 patients received radiographs of the knee joint in the outpatient clinic at our institution between October 2019 and April 2020, which were identified using our institutional electronic database. Patients were selected according to the following exclusion criteria: patients < 18 years of age, radiographs that were not performed in our institution, patients who underwent previous knee surgical procedure, scarce visualization of the joint line (e.g., no properly extended knee). Following the exclusion criteria, we randomly enrolled 200 plain radiographs for evaluation. To achieve an "a-priori" demographic balance, we randomly assigned 100 female and 100 male patients, each group with 50 right knees and 50 left knees. Patient charts were reviewed to collect demographic and anthropometric characteristics of all patients.

\section{Radiological evaluation}


Using radiographs in antero-posterior (AP) projection, two observers performed an independent and blinded evaluation and measurement, using JiveX-5.2 Medicad program (VISUS Health IT GmbH Gesundheitscampus-Süd 15-17 44801 Bochum) as a DICOM manager. Measurements were conducted twice within a time interval of two weeks. One of the observers was a senior resident in orthopaedics and the second observer a physician in training. This study design allowed us to examine whether the reliability of the novel classification system at the tibia was dependent on the experience of the examiner. The following two measurements were performed: Initially, the inner diaphyseal diameter of the proximal tibia was quantified at $16 \mathrm{~cm}$ from the articular surface on the lateral plateau of the tibia, followed by the measurement of the diameter $3 \mathrm{~cm}$ below the medial tibial eminence (as shown in Figure 1).

\section{Novel classification system}

Patients were separated into male and female sex due to morphological differences. Both groups were further divided into three sub-groups according to the distal inner diaphyseal diameter using the 25th and 75th percentile as reference points to identify cut-off values for further classification: A: under percentile 25th, B: between percentile 25th and 75th, and C: over percentile $75^{\text {th }}$ (Tab.1; Fig 2).

Furthermore, an index ratio was calculated between the inner diaphyseal diameter at $16 \mathrm{~cm}$ and the medial tibial eminence diameter at $3 \mathrm{~cm}$ to classify male and female patients into three groups with the same percentile ranges as outlined above (Tab. 2; Fig. 3).

\section{Statistical analysis}

Recapitulatory data are given as median (range) for continuous variables and as frequency (percentage) for categorical variables. Mann-Whitney $U$ test was applied for continuous outcomes and revealed normal distribution. Statistical significance was set at a $p$-value $<0.05$. The intraclass correlation coefficient (ICC) was utilized to quantify the inter- and intra-observer reliability of all radiographic measurements. Here, ICC values greater than 0.90 indicate an excellent reliability. Pearson Correlation (linear regression test) was performed to identify a relation between our dependent and independent variables. The software IBM SPSS Statistics v26 (IBM Corp, Armonk, NY, USA) was employed for the statistical analysis.

\section{Results}

A total number of 197 patients (100 male and 97 female) with a median age of 68 years (range 21-89 years) were included for the final analysis. Three patients were excluded due to the impossibility to measure the inner diaphyseal diameter at $16 \mathrm{~cm}$. There were 47 left knees and 50 right knees in the female group and 50 left knees and 50 right knees in the male group. We identified a moderate correlation between the AP diameter and height $(r=0.568)$; a low correlation between the AP diameter and weight $(r$ $=0.376)$. The results furthermore showed a correlation between the AP diameter and BMI $(r=0.132)$ but no statistical significance (Fig.4). In line with this, there was no statistically significant correlation between the index ratio and height $(r=0.082)$ or weight $(r=0.014)$ or BMI $(r=-0.038)$ (Fig.5). 


\section{Radiological findings}

According to the 25th and 75th percentile and cut-off values for each sex (Tab. 1; Fig. 2), three groups of the anatomical classification of the distal tibia were created. Female patients: type $A:<13 \mathrm{~mm}$; type B: 13$17 \mathrm{~mm}$; and type $C . \geq 17 \mathrm{~mm}$. Male patients: type $A:<16 \mathrm{~mm}$; type $B: 16-20 \mathrm{~mm}$; and type $C$ : $\geq 20 \mathrm{~mm}$.

In conformity to the novel index ratio (inner diameter of the tibial canal $16 \mathrm{~cm}$ distal to the knee joint, in relation to the inner diameter of the medullary canal $3 \mathrm{~cm}$ distal to the medial tibial eminence in AP knee radiographs) three anatomical classification groups were constructed: female patients: type $A:<0.19$, type $B$ : 0.19-0.24, type $C>0.24$; male patients: type $A:<0.19$, type $B: 0.19-0.23$, type $C$. $>0.23$ (Tab. 2; Fig. 3). Significant differences for several AP diameters and the novel index ratio between the three types in male and female patients were observed (Tab. 3 ).

The median intra-rater agreement was 0.998 (95\% Cl 0.998-0.999) for rater 1 and 0.997 (95\% Cl 0.997$0.998)$ for rater 2 . The inter-observer assessment also demonstrated a high ICC of $0.998(95 \% \mathrm{Cl} 0.998-$ 0.998).

\section{Discussion}

Our series of measurements allows to divide the morphology of the proximal tibia into three groups: type $A, B$ and $C$, having type $C$ the wider inner diaphyseal canal; in addition, significant sex differences were reported. This novel index and classification could be useful in predicting the risk of aseptic loosening, thus orienting the surgeon towards the choice of a rotating hinge implant. Like the Citak classification [5], there are other classifications, such as the Dorr classification [11], which describe anatomical norm variations of bony structures.

According to cut-off values for each sex, the ratio between the inner diameter of the tibial canal $16 \mathrm{~cm}$ distal to the knee joint, in relation to the inner diameter of the medullary canal $3 \mathrm{~cm}$ distal to the medial tibial eminence in AP knee radiographs, lead to the development of three anatomical classification groups: female patients: type $A:<0.19$, type $B: 0.19-0.24$, type $C>0.24$; male patients: type $A:<0.19$, type $B$ : $0.19-0.23$, type $C .>0.23$, having type $C$ the wider inner diaphyseal canal.

Excellent inter- $(0.996-0.998)$ and intra-observer reliability $(0.92-0.997)$ was demonstrated, which we were able to validate in our study (inter-/intra-observer reliability $0.997-0.999 / 0.998$ ).

The femoral index resulting from the Citak classification was shown to be an independent predictor for aseptic femoral loosening of rotating hinge knee prosthesis [9]. The measurements of the diameter of the internal femoral canal as the basis of the Citak classification were transferred to the tibia in this study. Also, we classified it analogue to the Citak classification of the femur in type A, B and C with quantitative cut-off values for each group and with a similar distribution for each type.

Citak et al. proposed a new classification for distal femur that may be helpful as pre-operative planning for rotating hinge prosthesis. Male and female patients were separate in different groups due to AP 
diameter found for each group and three types were described. Male type $A$ with AP diameter under 19 , type $B$ between 19-24 and type $C, 24$ or above while female patients were classified as type $A$ below 15 , type $B$ between 15 and 20, and type $C, 20$ or greater values. High inter- and intra-observer reliability indicates the classification to be a useful tool in making decisions on whether a hinged prosthesis is the best choice for a patient considering the risk of (AL). Citak's classification for distal femur has an interobserver reliability between $0.996-0.998$ and an intra-observer reliability between $0.92-0.997$ similar to the intra- and inter-observer reliability found on this study of $0.997-0.999$ and 0.998 respectively, making it useful as a pre-operative tool for patient stratification. Also, we classified it analogue to the Citak classification of the femur in type $A, B$ and $C$ with quantitative cut-off values for each group and with a similar distribution for each type. In contrast to the novel classification system study, this study showed a moderate correlation between the AP diameter of proximal tibia and height. Although further investigation is needed, a type $C$ with a wider inner diaphyseal diameter of the tibial canal may be helpful to predict AL of the tibial component in TKA tibially as has been shown femorally [5]. It is suggested that its combined usage with the classification system for the distal femur facilitates decision-making processes regarding the implant and patient selection for rotating hinge implants.

Additionally, a novel index was developed; the distribution of the index ratio values demonstrated a wider range among the female study population, but similar cut-off values for both male and female patients. Ranging from $16 \%$ [12] to $65 \%$ [13], aseptic loosening has shown to be the most important cause of nonseptic failures. Moreover, it is well known that an appropriate cementing technique is mandatory, but is becoming clear that patient related factors, such as bone stock quality and diaphyseal canal morphology, play an important role in prosthesis fixation and survivorship. The presented high failure rates could be justified by the fact that knee prosthesis with fixed hinge suffers from excessive abnormal stresses, such as tension, compression, and shearing forces. These stresses are transferred from the prosthesis to the bone, applying mostly to the interface [7]. As suggested by Morgan-Jones et al. failure to gain adequate fixation in zone 2 (methaphysis) and 3 (diaphysis) can lead to early failure of a revision implant due to elevated shear stress; The concept of zonal fixation provides a working methodology applicable to both the tibia and the femur when planning revision knee replacement [14].

Taking this into account, the Citak classification system for distal femur offers a new possibility for patient stratification, evaluation and decision-making. Although no specific studies have been conducted focusing specifically on the tibial component alone, the use of both classification systems may be a better predictor for risk of $A L$ and a tool to choose what is best for patients individually, preventing unwanted outcomes.

This study obtains the following limitations: Firstly, it has intrinsic limitations related to the retrospective study design. Secondly, ethnic differences among the study population were not considered, despite the existing proof for gender and race differences in knee morphology as described by Kim et al. who reported important differences among sex and races on the tibial medio-lateral and antero-posterior dimensions, while Mahfouz et al. found an evident larger femoral AP diameter, with a smaller aspect ratio comparing Caucasian and East Asian population and a larger aspect ratio of the tibia emerged when 
comparing Caucasian and Black population $[15,16]$. Therefore, the generalizability of the study results is limited and needs further validation in other populations to increase external validity. Thirdly, analyses were carried out on randomly chosen radiographic images already stored in our database that were not adjusted-on-purpose or calibrated; however, all radiographs were performed according to a standardized methodology in our radiology department. The rationale behind that was to create a less controlled and more authentic setting suggesting higher external validity of the novel index. Lastly, the number of included patients was relatively low and requires further validation in larger multicenter studies to strengthen the level of evidence.

In conclusion, aseptic loosening represents the most frequent non-septic cause of rotating hinge knee prosthesis failure. It is well known that an appropriate fixation is mandatory, especially in a revision setting where it is difficult to have appropriate bone stock for increasing prosthesis' survivorship.

Ultimately, the presented study project should be replicated to further test reliability of the classification, as a predictor for aseptic loosening in revision cases with different prosthesis designs, as well as its effects on implant survivorship. Lastly, future research should investigate the relationship between the novel femur and tibia classification.

\section{Declarations}

\section{Author contribution}

All authors satisfy the four ICMJE Criteria as follows: substantial contributions to the conception or design of the work; or the acquisition, analysis, or interpretation of data for the work.

Drafting the work or revising it critically for important intellectual content.

Final approval of the version to be published.

Agreement to be accountable for all aspects of the work in ensuring that questions related to the accuracy or integrity of any part of the work are appropriately investigated and resolved.

Ethics approval and consent to participate Ethical Board Approval (2021-300061-WF).

Consent for publication N/A

\section{Conflict of Interest}

The authors declare that they have no conflict of interest regarding this manuscript. Independent from the submitted manuscript, received royalties/payments of all authors are listed: payments for presentations 
from Waldemar Link, Hamburg, Germany, Zimmer Biomet Inc., Warsaw, USA. Heraeus, Ceramtec Co.

\section{References}

1. Walldius B (1957) Arthroplasty of the knee using an endoprosthesis. Acta orthopaedica Scandinavica Supplementum 24:115-116. https://doi.org/10.3109/ORT.1957.28.SUPPL-24.01

2. Sonstegard DA, Kaufer H, Matthews LS (1977) The spherocentric knee: biomechanical testing and clinical trial. The Journal of bone and joint surgery American volume 59:602-616. https://doi.org/10.2106/00004623-197759050-00005

3. Kouk S, Rathod PA, Maheshwari AV, Deshmukh AJ (2018) Rotating hinge prosthesis for complex revision total knee arthroplasty: A review of the literature. Journal of clinical orthopaedics and trauma 9:29-33. https://doi.org/10.1016/J.JCOT.2017.11.020

4. Abdulkarim A, Keane A, Hu SY et al (2019) Rotating-hinge knee prosthesis as a viable option in primary surgery: Literature review \& meta-analysis. Orthopaedics and Traumatology: Surgery and Research 105:1351-1359

5. Citak M, Levent A, Suero EM et al (2021) A novel radiological classification system of the distal femur. Arch Orthop Trauma Surg. https://doi.org/10.1007/s00402-021-03828-w

6. sen Yang R, Lin HJ (2001) Contact stress on polyethylene components of a new rotating hinge with a spherical contact surface. Clin Biomech Elsevier Ltd 16:540-546. https://doi.org/10.1016/S02680033(01)00024-9

7. Kabo JM, sen Yang R, Dorey FJ, Eckardt JJ (1997) In vivo rotational stability of the kinematic rotating hinge knee prosthesis. Clin Orthop Relat Res 166-176. https://doi.org/10.1097/00003086199703000-00024

8. Correia J, Kendoff D, Klatte TO et al (2014) Percutaneous cementation: A case of a failed treatment of a loose revision total knee arthroplasty. Technol Health Care 22:645-650. https://doi.org/10.3233/THC-140810

9. Levent A, Suero EM, Gehrke T, Citak M (2021) Risk Factors for Aseptic Loosening After Total Knee Arthroplasty with a Rotating-Hinge Implant: A Case-Control Study. The Journal of bone and joint surgery American volume 103:517-523. https://doi.org/10.2106/JBJS.20.00788

10. Levent A, Suero EM, Gehrke T et al (2021) Risk factors for aseptic loosening in complex revision total knee arthroplasty using rotating hinge implants. Int Orthop 45:125-132. https://doi.org/10.1007/S00264-020-04878-2

11. Dorr LD, Faugere MC, Mackel AM et al (1993) Structural and cellular assessment of bone quality of proximal femur. Bone 14:231-242. https://doi.org/10.1016/8756-3282(93)90146-2

12. Farid YR, Thakral R, Finn HA (2015) Intermediate-Term Results of 142 Single-Design, Rotating-Hinge Implants: Frequent Complications May Not Preclude Salvage of Severely Affected Knees. J Arthroplasty 30:2173-2180. https://doi.org/10.1016/j.arth.2015.06.033 
13. Cottino U, Abdel MP, Perry KI et al (2017) Long-term results after total knee arthroplasty with contemporary rotating-hinge prostheses. Journal of Bone and Joint Surgery - American Volume 99:324-330

14. Morgan-Jones R, Oussedik SIS, Graichen H, Haddad FS (2015) Zonal fixation in revision total knee arthroplasty. Bone and Joint Journal 97-B:147-149

15. Mahfouz M, Elhak E, Fatah Bsc A et al (2011) Three-dimensional Morphology of the Knee. https://doi.org/10.1007/s11999-011-2089-2. Reveals Ethnic Differences

16. Kim TK, Phillips Bsc M, Bhandari M et al (1999) What Differences in Morphologic Features of the Knee Exist Among Patients of Various Races? https://doi.org/10.1007/s11999-016-5097-4. A Systematic Review

\section{Tables}

Tab. 1 The cutoff values for the inner diaphyseal diameter at $16 \mathrm{~cm}$ from the articular surface, from both men and women

Tab. 2 The index intervals used for classifying patients on each group depending on sex

Tab. 3 Patients' characteristics by novel classification group

\begin{tabular}{ccc}
\hline Inner Tibial Diameter & Male & Female \\
\hline Group $A$ & $<16$ & $<13$ \\
Group $B$ & $16-20$ & $13-17$ \\
Group $C$ & $\geq 20$ & $\geq 17$ \\
\hline
\end{tabular}

Tab. 1

\begin{tabular}{ccc}
\hline Index & Male & Female \\
\hline Group $A$ & $<0.195$ & $<0.191$ \\
Group B & $0.195-0.234$ & $0.191-0.236$ \\
Group C & $\geq 0.234$ & $\geq 0.236$ \\
\hline
\end{tabular}

Tab. 2 


\begin{tabular}{|c|c|c|c|c|c|c|}
\hline \multirow[b]{2}{*}{ Variables } & \multicolumn{3}{|c|}{ Male } & \multicolumn{3}{|c|}{ Female } \\
\hline & Group A & Group B & Group C & Group A & Group B & Group C \\
\hline Number of patients & 25 & 50 & 24 & 17 & 54 & 26 \\
\hline (years) (median[range]) & $69[22-83]$ & $69[44-88]$ & 66.5 [49-89] & $67.5[51-88]$ & $69[48-90]$ & $69[52-84]$ \\
\hline ght (cm) (median[range]) & $172[164-187]$ & 178 [163-193] & $180[168-191]$ & $159[149-180]$ & $165[152-174]$ & $166[154-181]$ \\
\hline ight (Kg) (median[range]) & $82[71-123]$ & $93[65-128]$ & $101[70-130]$ & $73[63-115]$ & $80[50-108]$ & $81[58-119]$ \\
\hline BMI (median[range]) & $27.5[21.7-40.2]$ & $28.2[22.1-42.4]$ & $30.1[22.1-39.2]$ & $\begin{array}{c}30.6[24.6- \\
37.6]\end{array}$ & $\begin{array}{c}27.73[18.9- \\
37.7]\end{array}$ & $28[21.8-44.2]$ \\
\hline Side Left/Right & $13 / 12$ & $27 / 23$ & $10 / 14$ & $7 / 10$ & $29 / 25$ & $11 / 15$ \\
\hline $\begin{array}{c}\text { AP Diameter }(\mathrm{cm}) \\
\text { (median[range]) }\end{array}$ & $15.3[13.3-15.9]$ & $17.95[16-19.8]$ & $21.6[20-25.1]$ & $\begin{array}{c}11.9[10.3- \\
12.9]\end{array}$ & $14.7[13.1-16.9]$ & $17.8[17-22]$ \\
\hline $\begin{array}{l}\text { Novel Index ratio } \\
\text { (median[range]) }\end{array}$ & $\begin{array}{c}0.187[0.171- \\
0.215]\end{array}$ & $\begin{array}{c}0.211[0.184- \\
0.265]\end{array}$ & $\begin{array}{c}0.243[0.222- \\
0.276]\end{array}$ & $\begin{array}{l}0.18[0.158- \\
\quad 0.232]\end{array}$ & $\begin{array}{c}0.218[0.176- \\
0.284]\end{array}$ & $\begin{array}{c}0.244[0.201- \\
0.280]\end{array}$ \\
\hline
\end{tabular}

Tab. 3

Figures

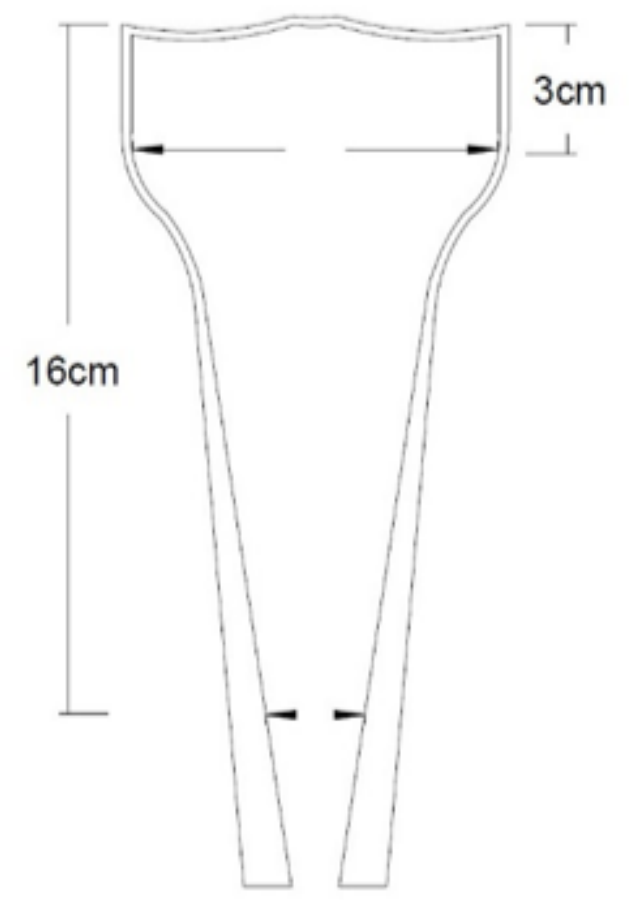

Figure 1 
Methods of measurement, proximal tibia at $3 \mathrm{~cm}$ and tibia shaft at $16 \mathrm{~cm}$ from medial spine

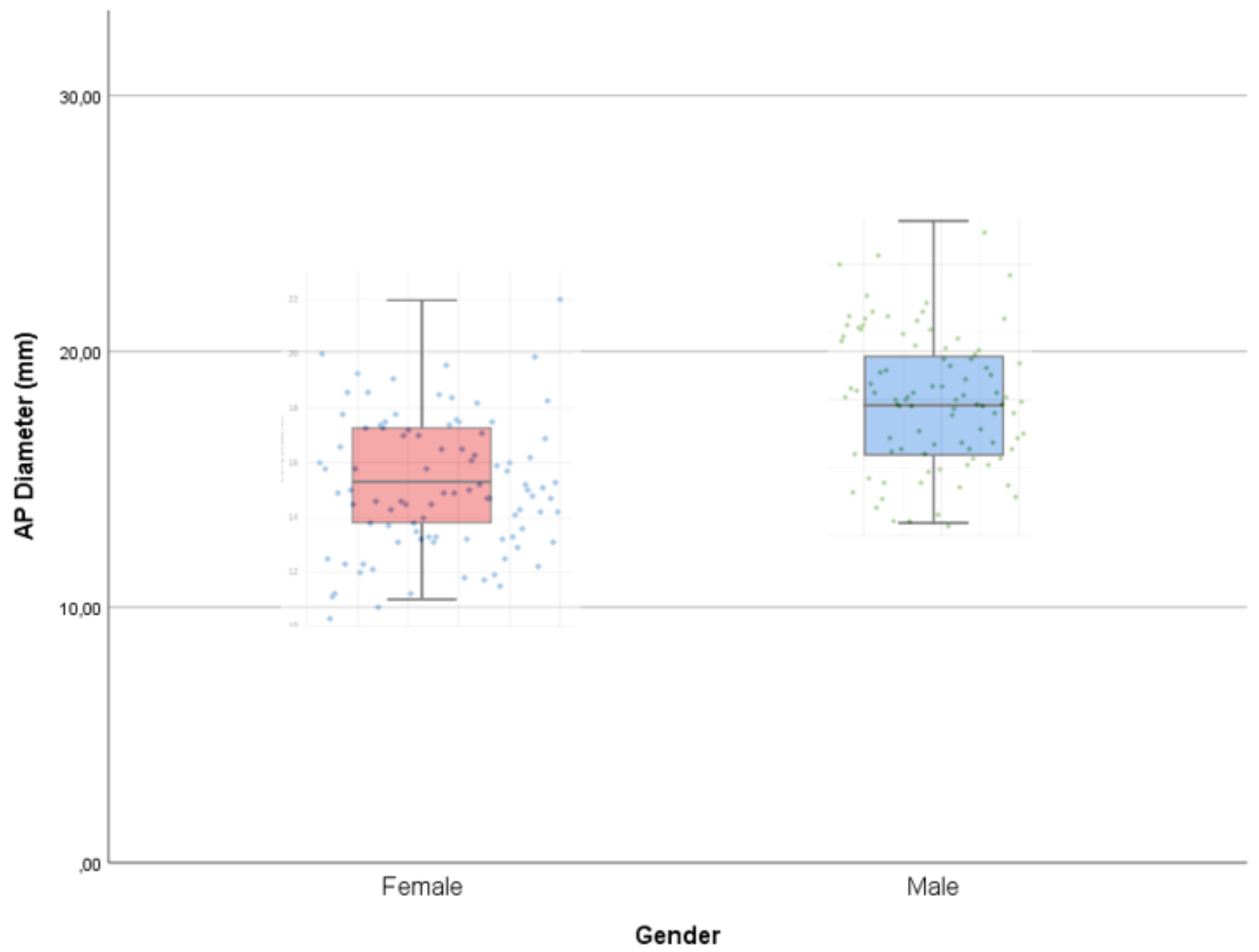

Figure 2

Distribution of AP diameter of the distal femur by sex 


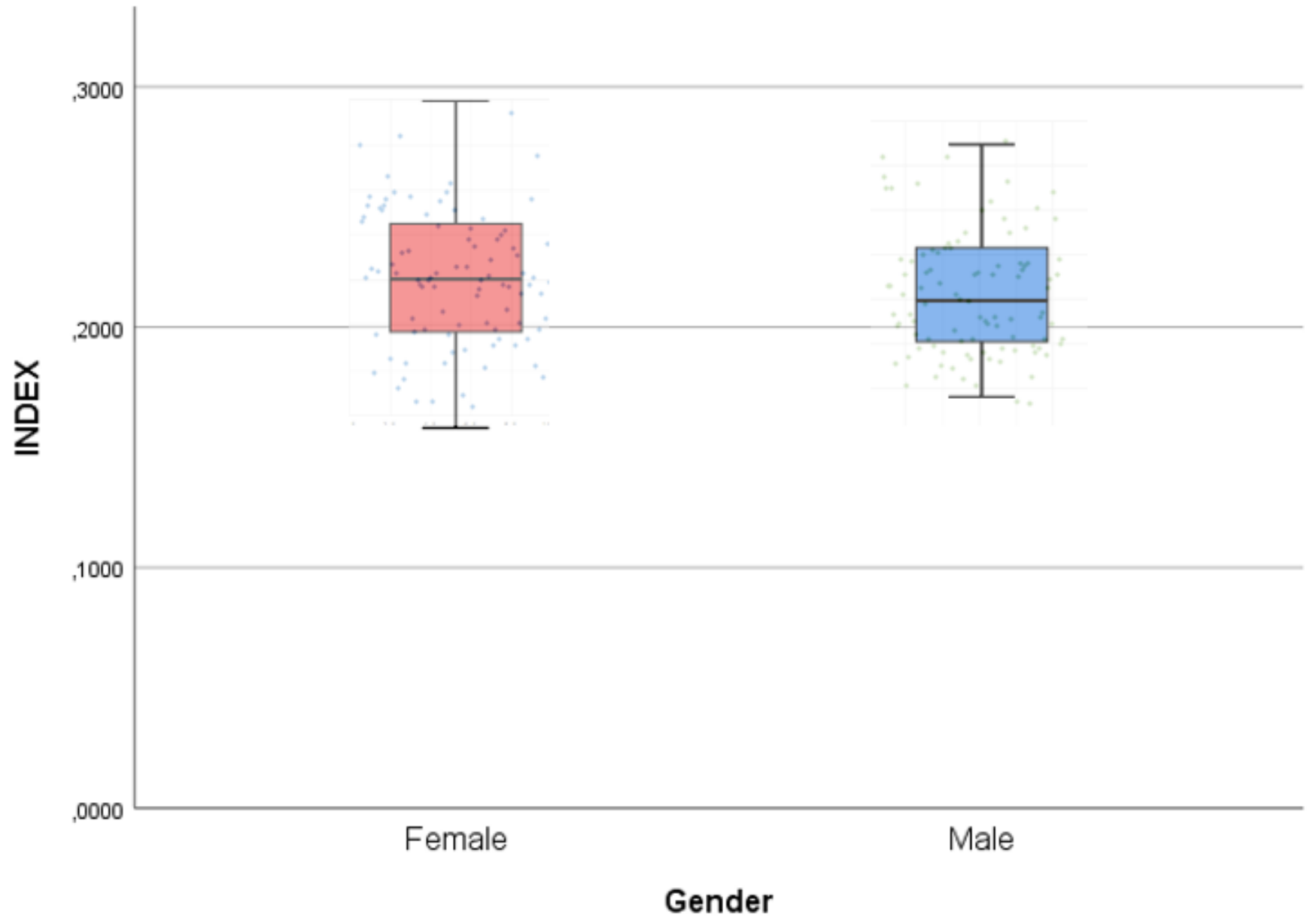

Figure 3

Distribution of novel index by sex 


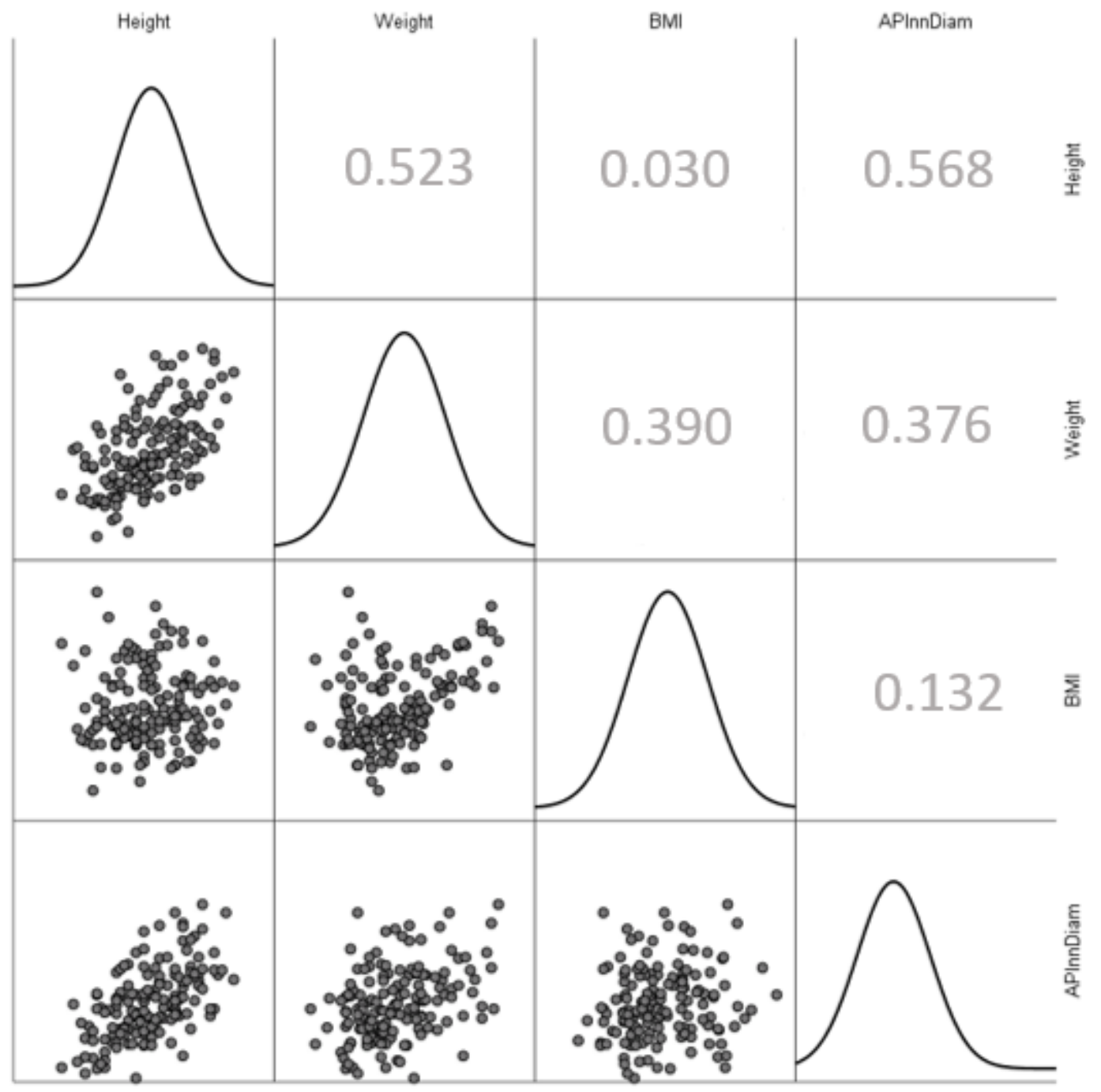

Figure 4

Presents the correlation analysis between AP diameter and height, weight, and BMI 


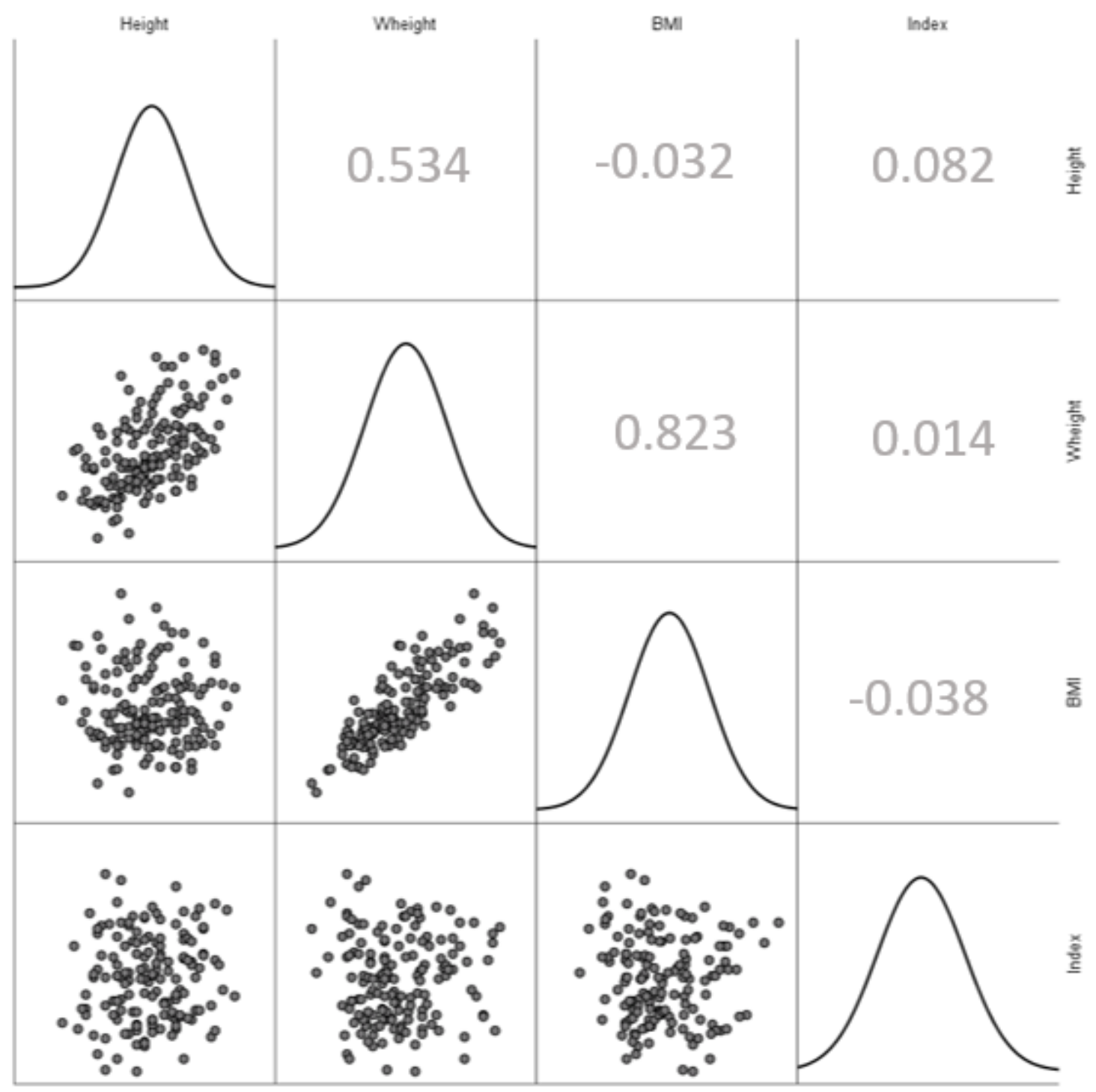

Figure 5

Presents the correlation analysis between the novel Index and height, weight and BMI 